whether infection may possibly or probably be conveyed by any given mode of administering holy communion is one for medical experts only ; it is foolish for anyone else to give an opinion. It has, indeed, been suggested that communicants, obeying a Divine command, may commit themselves to the Divine protection against possible harm. I cannot put that suggestion summarily aside, because $I$ believe in what is commonly called "miracle" as possible and not un. frequent; but $I$ should meet it by a reminder of the theological commonplace that miracle must not be unnecessarily presumed either as an explanation of fact or as a guide to action; such presumption, therefore, is no excuse for doing a dangerous thing which is avoidable. It is technically presumptuous to hope for miraculous protection without taking all natural precautions. It is for medical experts alone to say whether any given precaution be adequate.

Is the peril, then, avoidable? If our actual practice be dangerous it is for ritual authorities to consider what may be substituted. There seems to be a tendency in some quarters to assume that no change can be made. I cannot understand this. Theologically speaking, it is to me inconceivable that God, Who reveals to scientific research the hidden perils of nature, has tied the administration of His Sacrament to a mode which that revelation shows to be harmful. Practically speaking, there are several modes of administration known in the Church. Careful consideration of the question will certainly be demanded. The Church Times was lately urging the Fnglish bishops to appoint a commission of inquiry. Even at the present stage of discussion it may be useful to recall the methods used.

In the greater part of the Eastern Church the method of intinction prevails, to which you have already referred. A kind of sop is made in the chalice, which is administered by a spoon. I believe the spoon is rinsed after each using, with what effect the proper experts may say. This method is not perhaps very likely to find favour with us.

In the West, before the withdrawal of the cup from the laity in the twelfth and following centuries, the sacred species was often administered by suction through a fistula or metal tube. This would probably be even more open to objection than our practice, in which the lower lip only comes into bare contact with the outside of the cup.

Early in the eighth century the Pope, St. Gregory II., forbad the use of many chalices on the altar for symbolical reasons, requiring all to communicate from one cup. This brought in the use of very large vessels, from which the sacred species was poured into smaller cups, called scyphi, for the communion of the people. This may show that no theological or ritual exception can be taken to the use of a separate cup for each person, advocated by your American correspondent, but there is an overwhelming practical objection where any large number is concerned. The rule of the English Church requires the total consumption of the consecrated species by the priest, alone or with the help of some communicants. This cannot be effected save by the usual practice of pouring into the cup some wine or water, or both, and drinking this. The treatment of several hundred cups passes imagination.

There is a practice, not formally adopted, so far as I know, anywhere in the Church, but sometimes followed by individual priests in difficult cases of clinical communion, which may be worth mentioning. A particle of the species of bread is slightly tinged in the chalice and then laid on the tongue of the communicant. This method of giving communion presents little practical difficulty and might conceivably be adopted by authority for general use.

Some of your readers may be glad to have this material to work upon in their character of medical experts.

I am, Sirs, yours faithfully,

Madingley Vicarage, Cambridge, Nov. 28th. T. A. LACEY.

\section{BERI-BERI AND CHRONIC ARSENICAL POISONING.}

To the Eaitors of THE LANCET.

SIRs, - I trust that you will allow me to call attention in your columns to a point of some interest in connexion with tropical medicine raised by the present epidemic of peripheral neuritis in Chester and Manchester. The extraordinary similarity of some of the cases to certain phases of beri-beri seems to me to suggest the question whether many instances attributed to the latter disease may not really be due to chronic arsenical poisoning. Owing to the kindness of several medical gentlemen I had the opportunity of examining pretty carefully 10 of the Chester cases, and also of seeing several of those which had occurred at Manchester. I certainly thought that Dr. W. A. Newall and Dr. J. R. Prytherch of Chester were abundantly justified in noting an extreme resemblance between their cases and cases of beri-beri. The local anæsthesias, especially of the feet, of the tibial skin, and of the finger-tips, the dropsy over the tibire, the tenderness of the calf muscles, the loss of the deep reflexes, the ataxia combined with paresis, even the peculiar spacing of the heart-sounds in some instances, were all so suggestive that had the cases occurred in a beri-beri region I believe few medical men would not have returned them under that heading.

Assuming the cases to be due to chronic arsenical poisoning, we may well ask whether similar epidemics occurring in the East or on board ships may not often have been wrongly attributed to beri-beri. The possibilities of arsenical poisoning on vessels are too obvious to need reference in detail. Natives of India and Burma are very fond of lemonade which is manufactured from European chemicalsprobably of the cheapest sort. They also often delight in tinned and bottled fruits. The occupants of jails, hospitals, and asylums may suffer from arsenical poisoning through half a dozen routes. The sudden disappearance of beri-beri from the Japanese navy after a general change of diet is certainly suggestive. It has long been thought on epidemiological grounds that beri-beri may be due to some form of foodpoisoning; it now seems just possible that the poison may be, at least in some cases, nothing but arsenic. The sudden improvement occurring in most cases after removal from the house where they contracted the malady is certainly more suggestive of intoxication than of infection. In short, regarding such epidemics of beri-beri as I have had the opportunity of witnessing, I should be sorry to be called upon to give a definite statement to the effect that they were not due to chronic arsenical poisoning.

Of course there may be, and very probably so, a true beriberi, but the points of distinction do not seem to be very clearly established at present. I think I remember bullie and even pigmentation in India. Certainly cases approxi. mating to the "wet "form of beri-beri do not seem to have been noted in Chester; but this is, I think, a later stage of the disease, and may perhaps have been overlooked in chronic arsenical poisoning. Lastly, our knowledge of the epidemiology of beri-beri cannot be said to be so complete as to enable us to exclude all possibility of arsenic being concerned in the causation at least of many cases attributed to the disease

In conclusion, I hope that it will be understood that I am only suggesting a possibility and that $I$ do not presume to erect a theory. The next ship which arrives infected with beri-beri at an English port will afford an opportunity for an examination of the question.

Liverpool, Nov. 30th, 1900.

I am, Sirs, yours faithfully, RONALD ROSS, D.P.H.

\section{"THE TREATMENT OF SPRAINS AND OF SOME FRACTURES."}

To the Editors of THE LANCET.

Sras,-For the last 20 years I have been treating sprains by the application of adhesive plaster and, like $\mathrm{Mr}$. Christopher Heath, I have found this plan far more satisfactory than the older methods. Since I first became aware of its value I have never omitted to use this plaster in some stage or other of the treatment of these injuries, even in sprains accompanying fractures. I was first led to realise the advantages likely to result from so firm and steady a support as that effected by adhesive plaster when studying cedematous tissues microscopicaily for the purpose of the "Atlas of Histology." The plasma which in cudema is infiltrated into the connective tissue, separating almost every individual bundle from the others, seemed likely not only to prevent repair by its pressure, but also (from lack of complete absorption) to produce permanent thickening of the tissues by becoming organised.' This condition pointed to the desirability of preventing, if possible, this infiltration from taking place, and if it had already taken place of promoting its absorption, and the firm support without undue

1 Atlas of Histology, Plate VIII., Fig. 14. 